\title{
Dinamika psikologis efikasi diri terhadap intensi perilaku seks pranikah pada remaja
}

\author{
Birrulwalidaini \\ Magister Psikologi, Program Pascasarjana, Universitas Ahmad Dahlan, Yogyakarta \\ asadlurrib@gmail.com \\ Hadi Suyono \\ Magister Psikologi, Program Pascasarjana Universitas Ahmad Dahlan Yogyakarta \\ hatijernih06@gmail.com \\ Fatwa Tentama \\ Magister Psikologi, Program Pascasarjana Universitas Ahmad Dahlan Yogyakarta \\ fatwa.tentama@psy.uad.ac.id
}

\begin{abstract}
ABSTRAK
Perilaku seks pranikah di kalangan remaja saat ini sangat memprihatinkan. Perilaku seks pranikah dapat terjadi ketika remaja yang memiliki pergaulan bebas dengan teman dan tidak dapat mengatur perilaku diri sendiri. Perilaku seseorang dipengaruhi oleh faktor motivasional di dalam diri yang disebut dengan intensi. Intensi merupakan indikasi seberapa besar individu akan berusaha untuk memunculkan perilaku, yang dalam hal ini adalah perilaku seks pranikah. Tujuan dari penelitian ini untuk mengetahui pemahaman mengenai dinamika psikologis efikasi diri terhadap intensi perilaku seks pranikah pada remaja. Penelitian ini menggunakan metode kualitatif dengan pendekatan deskriptif analitis. Berdasarkan hasil analisis deskriptif bahwa efikasi diri memberikan kontribusi terhadap intensi perilaku seks pranikah pada remaja. Remaja yang memiliki efikasi diri yang tinggi memiliki kemampuan untuk mengurangi perilaku seks pranikah. Kesimpulan dari penelitian ini bahwa secara dinamika psikologis efikasi diri mampu menjelaskan intensi perilaku seks pranikah pada remaja.
\end{abstract}

Kata Kunci: Efikasi Diri, Intensi, Perilaku Seks Pranikah, Remaja

\begin{abstract}
Premarital sexual behavior among adolescents is currently very alarming. Premarital sexual behavior can occur when teenagers who have free sex with friends and cannot regulate their own behavior. A person's behavior is influenced by motivational factors in oneself called intention. Intention is an indication of how much the individual will try to emerge behavior, which in this case is premarital sexual behavior. The purpose of this study was to find out an understanding of the psychological dynamics of self-efficacy towards the intention of premarital sex behavior in adolescents. This research uses a qualitative method with a descriptive analytical approach. Based on the results of descriptive analysis that self-efficacy contributes to the intentions of premarital sexual behavior in adolescents. Adolescents who have high self-efficacy have the ability to reduce premarital sexual behavior. The conclusion of this study is that the psychological dynamics of self-efficacy can explain the intention of premarital sex behavior in adolescents.
\end{abstract}

Key Words: Adolescent, Intention, Premarital Sex Behaviour, Self Efficacy

Birrulwalidaini, email: asadlurrib@gmail.com 
Jurnal Psikologi Terapan dan Pendidikan

ISSN: $2715-2456$

Vol. 1, No. 1, Mei 2019, pp. 45-53

\section{PENDAHULUAN}

Masa remaja merupakan periode transisi dari masa kanak-kanak menuju dewasa yang dimulai pada usia 10-12 tahun dan berakhir pada usia 18-20 tahun. Pada masa transisi ini, remaja banyak mengalami perubahan yang meliputi perubahan fisik, kognisi, emosi, maupun sosial. Perubahan yang paling khas pada masa remaja adalah pubertas. Pubertas merupakan sebuah proses kematangan fisik yang berlangsung cepat melibatkan perubahan hormonal, dan tubuh (Santrock, 2012).

Secara psikologis, remaja merupakan masa yang kritis dalam proses menuju dewasa. Dewasa secara seksual melibatkan sejumlah hal yang sesungguhnya memiliki akar instingtual. Anak lelaki saling berkompetisi untuk menarik perhatian perempuan dengan memperlihatkan kemampuan fisik dan keberanian. Sementara anak perempuan bersaing menarik perhatian anak lelaki dengan berupaya memperbaiki penampilan diri (Boeree, 2017).

Pada masa remaja sangat beresiko terhadap masalah-masalah kesehatan reproduksi seperti perilaku seks pranikah, NAPZA, dan HIV/AIDS (BKKBN, 2016). Seks pranikah merupakan perilaku seksual yang dilakukan tanpa melalui proses pernikahan (Cavendish, 2010). Djamba (2013) mengatakan bahwa seks pranikah merupakan aktivitas perilaku seksual yang dilakukan oleh individu dengan orang lain sebelum menikah. Sarwono (2016) juga menambahkan perilaku seksual merupakan segala tingkah laku yang didorong oleh hasrat seksual, yang dilakukan dengan lawan jenis ataupun sesama jenis.

Perilaku seks pranikah yang dilakukan remaja semakin meningkat. Hasil Survei yang dilakukan oleh Idaho Youth Risk Behavior Survey (YRBS) secara nasional di Amerika Serikat pada tahun 2017 didapatkan bahwa 35,1\% pelajar yang duduk di kelas 9-12 pernah melakukan hubungan seks pranikah, $16,5 \%$ pelajar tersebut menggunakan obat-obatan atau alkohol sebelum berhubungan seks. Huang, Murphy, dan Hser (2011) mengatakan bahwa sebagian besar remaja aktif secara seksual pada usia 14-18 tahun. Perilaku seks pranikah di kalangan remaja Indonesia saat ini juga sangat memprihatinkan. Hal ini berdasarkan data dari Komisi Perlindungan Anak (KPAI) bahwa remaja usia 14 hingga 18 tahun di kota besar di Indonesia diketahui pernah berhubungan seksual pranikah sebanyak $32 \%$ dan 62,7 \% remaja kehilangan keperawanannya saat masih duduk di bangku SMP, bahkan 21,2 \% diantaranya ekstrim, yakni pernah melakukan aborsi (KPAI, 2013).

Perilaku seks pranikah yang dilakukan oleh remaja memberikan dampak pada aspek psikologis dan kesehatan (Irianto, 2015). Perilaku seks pranikah tidak hanya memberikan dampak pada remaja untuk terinfeksi IMS, termasuk HIV/AIDS, tetapi juga kehamilan yang tidak diinginkan pada wanita, yang dapat menyebabkan masalah kesehatan, sosial dan ekonomi yang serius (Bogale \& Seme, 2014). Kementerian Kesehatan (Kemenkes) tahun 2013 memaparkan bahwa 20\% dari 94.270 perempuan yang

Birrulwalidaini, email: asadlurrib@gmail.com 
Jurnal Psikologi Terapan dan Pendidikan

ISSN: $2715-2456$

Vol. 1, No. 1, Mei 2019, pp. 45-53

mengalami hamil di luar nikah berasal dari kelompok usia remaja dan $21 \%$ diantaranya pernah melakukan aborsi.

Perilaku seks pranikah dapat terjadi ketika remaja yang memiliki pergaulan bebas dengan temannya dan remaja tersebut tidak dapat mengatur perilaku diri sendiri. Menurut Ajzen (2005) perilaku seseorang dipengaruhi oleh faktor motivasional di dalam diri yang disebut dengan intensi. Sarwono (2016) menjelaskan bahwa intensi diartikan sebagai kecenderungan bertingkah laku dan merupakan indikasi seberapa besar individu akan berusaha untuk memunculkan perilaku. Ajzen (2005) menambahkan bahwa intensi menjadi faktor utama terjadinya perilaku yang terbentuk dari tiga determinan, yakni sikap, subjective norm, dan perceived behavioral control.

Berbagai temuan ilmiah menujukkan bahwa prediktor sikap, subjective norm, dan perceived behavioral control yang berpijak pada theory of planed behavioral (TPB) dapat memprediksi terjadinya sesuatu perilaku tertentu, yang didalamnya termasuk intensi perilaku seks pranikah pada remaja. Secara konseptual hubungan meta analisis yang bersumber dari pendapat Ajzen (2005) menjelaskan bahwa intensi memiliki akurasi yang tinggi dalam memprediksi perilaku. Pada dasarnya intensi perilaku seks pranikah adalah dorongan yang ada dalam diri individu yang mengatur terjadinya aktivitas seksual tanpa memperhatikan nilai dan norma masyarakat (Lange, Kruglanski, \& Higgins, 2012; Crooks \& Baur, 2013).

Hal ini diperkuat dengan adanya studi literatur pada 69 published review yang dilakukan oleh Buhi dan Goodson (2007) terkait dengan prediktor perilaku seksual pada remaja. Adapun hasil yang di dapatkan adalah intensi, perceived norm, dan faktor lingkungan menjadi prediktor stabil dari perilaku seks pranikah pada remaja. Penelitian Weeb dan Sheeran (2006) juga mengatakan adanya korelasi antara ukuran intensi dan ukuran perilaku. Hal ini menunjukkan bahwa intervensi yang menghasilkan intensi yang lebih besar mengubah efek yang lebih besar juga pada perilaku.

Intensi perilaku seks pranikah pada remaja disebabkan oleh efikasi diri (Cha, Doswell, Kim, Prochownik, \& Patrick, 2007; Rosdarni, Dasuki, \& Waluyo, 2015; Reuben, Obayemi, \& Oluwatosin, 2016). Efikasi diri merupakan faktor penentu tindakan manusia (human agency) terhadap apa yang dipikirkan, dipercaya dan dirasakan individu kemudian mempengaruhi untuk bertindak (Bandura, 2002). Selanjutnya Alwisol (2010) mendeskripsikan efikasi diri sebagai penilaian akan kemampuan diri. Penelitian yang dilakukan oleh Chilisa, Tihabano, Vista, Pheko, Losike, Mosime, Mpeta, dan Balogun (2013) juga membuktikan bahwa efikasi diri memiliki kekuatan memprediksi terjadinya perilaku seks yang aman pada remaja.

Penelitian MacNeil dan Byers (2009) mengatakan bahwa individu dengan tingkat efikasi diri seksual yang tinggi mampu mengatakan keinginannya termasuk menolak untuk melakukan seks pranikah. Hasil penelitian Rosdarni, Dasuki dan Waluyo (2015) juga mengatakan bahwa remaja yang memiliki 
Jurnal Psikologi Terapan dan Pendidikan

ISSN: $2715-2456$

Vol. 1, No. 1, Mei 2019, pp. 45-53

efikasi diri yang rendah beresiko untuk melakukan perilaku seks pranikah dibandingkan dengan remaja yang memiliki efikasi diri yang tinggi. Tsai, Chuang, Liang, dan Tsai (2011) menambahkan bahwa kurangnya efikasi diri dapat mengakibatkan individu memiliki aspirasi rendah, tidak berusaha lebih keras dan bahkan menyerah dengan mudah. Efikasi diri yang rendah pada remaja dapat terjadi karena individu belum mengenali potensi dirinya. Untuk itu diperlukan adanya upaya untuk meningkatkan efikasi diri pada remaja agar terhindar dari perilaku seks pranikah.

Dimotakis, Mitchell, dan Maurer (2017) dalam penelitiannya mengatakan bahwa individu yang memiliki banyak dukungan akan meningkatkan keyakinan dirinya dan berdampak pada efikasi diri yang positif. Penelitian Sherf dan Morrison (2019) membuktikan adanya hubungan antara efikasi diri dengan pemberian penilaian dari orang lain. Dukungan dari orang lain terhadap kemampuan diri yang dimiliki remaja mampu meningkatkan keyakinannya untuk tidak melakukan perilaku seks pranikah. Ayodele, Omolayo dan Bose (2011) membuktikan dukungan dan latar belakang keluarga memiliki peranan penting dalam keterlibatan remaja terhadap perilaku seks pranikah. Watofa, Suryanto dan Basuki (2019) menambahkan faktor keluarga, religiusitas dan sistem nilai individu merupakan faktor penting dalam mencegah perilaku seksual pranikah.

Berdasarkan penjelasan yang telah dipaparkan sebelumnya, adapun tujuan dari penelitian ini adalah untuk mengkaji dinamika psikologis efikasi diri terhadap intensi perilaku seks pranikah pada remaja.

\section{METODE PENELITIAN}

Penelitian dan strategi penyelidikan (strategi of inquiry) dalam penelitian ini menggunakan metode kualitatif dengan pendekatan deskriptif analitis. Menurut Sugiyono (2015) metode deskriptif analitis merupakan metode penelitian yang bertujuan mendeskripsikan atau memberi gambaran terhadap suatu objek penelitian yang diteliti melalui sampel atau data yang telah terkumpul kemudian membuat kesimpulan yang berlaku umum.

Analisis deskriptif dalam penelitian ini menggunakan dokumen tertulis yang berupa jurnal penelitian dan kajian teori mengenai efikasi diri dan intensi perilaku seks pranikah. Berdasarkan metode yang digunakan, penelitian ini bermaksud untuk memahami aspek yang melatarbelakangi remaja melakukan perilaku seks pranikah yaitu efikasi diri. Sebagaimana hal ini juga pernah dilakukan oleh Suyono (2011) tentang studi deskriptif mengenai konflik pemilukada menggunakan pendekatan studi kasus.

Birrulwalidaini, email: asadlurrib@gmail.com 
Jurnal Psikologi Terapan dan Pendidikan

ISSN: $2715-2456$

Vol. 1, No. 1, Mei 2019, pp. 45-53

\section{HASIL DAN PEMBAHASAN}

Berdasarkan hasil analisis deskriptif bahwa efikasi diri memiliki kontribusi dalam membentuk intensi perilaku seks pranikah pada remaja. Efikasi diri yang lemah akan mendorong remaja untuk memunculkan intensi dalam bentuk perilaku yang dalam hal ini adalah perilaku seks pranikah. Hal ini berdasarkan pemahaman bahwa pada masa remaja terjadi perubahan fisik yang sangat cepat, namun perubahan tersebut seringkali tidak sejalan dengan perkembangan psikologis, sehingga mempengaruhi kemampuan pengambilan keputusan remaja termasuk melakukan tindakan berisiko (Santrock, 2012). Hal ini terjadi karena adanya rasa ingin tahu yang besar, dan keinginan untuk mencoba sesuatu hal yang baru termasuk perilaku seks pranikah. Oleh karena itu, periode remaja merupakan masa yang rentan dalam proses perkembangannya. Perilaku seks pranikah ditentukan oleh seberapa besar intensi remaja untuk melakukannya, semakin besar intensi maka semakin besar pula kemungkinan individu untuk memunculkannya dalam perilaku tertentu.

Efikasi diri penting dimiliki oleh remaja agar mampu menghadapi segala perubahan yang terjadi, dengan memiliki efikasi diri yang tinggi, maka remaja memiliki keyakinan yang kuat untuk selalu dapat menghadapi segala perubahan serta tanggung jawab yang dimiliki dalam menghadapi masa-masa perkembangan dalam kehidupannya (Abousselam, 2005). Remaja yang memiliki efikasi diri yang tinggi akan menunjukkan antusiasme dan kepercayaan diri yang kuat dalam kesehariannya (Baron \& Byrne, 2005). Semakin tinggi efikasi diri individu, semakin individu percaya akan kemampuannya untuk berhasil dalam suatu tugas dan akan berusaha keras dalam menghadapi tantangan yang ada. Sebaliknya, individu dengan efikasi diri yang rendah cenderung akan mengurangi usahanya atau menyerah sama sekali.

Konsep efikasi diri merupakan komponen inti dari teori social cognitive yang dikemukakan oleh Bandura yang menekankan peran belajar observasional, pengalaman sosial, dan determinisme timbal balik dalam pengembangan kepribadian (Suwarni, 2016). Efikasi diri merupakan bagian dari pengetahuan tentang diri yang paling berpengaruh dalam kehidupan sehari-hari. Bandura (2010) menjelaskan bahwa efikasi diri berpengaruh besar terhadap perilaku. Hal ini dikarenakan efikasi diri mempengaruhi individu dalam menentukan setiap tindakan yang akan dilakukan. Efikasi diri juga berperan dalam mencapai tujuan termasuk di dalamnya perkiraan berbagai kejadian yang akan dihadapi.

Efikasi diri mempengaruhi mekanisme perilaku individu, apabila individu yakin mempunyai kemampuan untuk menghasilkan sesuatu yang diinginkan maka individu akan berusaha untuk mencapainya. Efikasi diri penting dimiliki oleh remaja agar mampu terus menghadapi segala perubahan yang terjadi (Winarni, 2017). Efikasi diri dapat diubah, dibentuk, ditingkatkan atau diturunkan berdasarkan salah satu atau kombinasi dari empat sumber yang mempengaruhi efikasi diri, yaitu (1) mastery experience, pengalaman-pengalaman yang dialami individu secara langsung, (2) vicarious 
Jurnal Psikologi Terapan dan Pendidikan

ISSN: $2715-2456$

Vol. 1, No. 1, Mei 2019, pp. 45-53

experience, individu yang melihat orang lain berhasil dalam melakukan aktivitas yang sama dan memiliki kemampuan yang sebanding, (3) persuasi verbal, nasehat dan bimbingan yang realistis dapat membuat individu yakin bahwa ia memiliki kemampuan, dan (4) keadaan fisiologis dan emosional (Alwisol, 2010).

Menurut Bandura (2010) terbentuknya keyakinan diri akan mempengaruhi fungsi koginitif, motivasi, emosional dan selektif individu dalam memandang suatu permasalahan. Permasalahan yang dihadapi dalam hal ini adalah mengendalikan dorongan seks pranikah dan mampu mengubahnya kedalam hal yang lebih positif. Individu dengan efikasi diri yang tinggi mempunyai persepsi positif terhadap dirinya sendiri termasuk dalam mengendalikan dorongan perilaku seks pranikah.

Dalam proses kognitif menjelaskan bahwa penetapan tujuan pribadi dipengaruhi oleh penilaian kemampuan diri. Semakin kuat efikasi diri, semakin tinggi tujuan yang ditetapkan oleh individu bagi dirinya sendiri, adapun yang memperkuat hal tersebut yakni komitmen individu terhadap tujuan tersebut. Selanjutnya pada proses motivasi, individu menuntun tindakan-tindakannya dengan menggunakan pemikiran tentang masa depan sehingga individu tersebut akan membentuk kepercayaan mengenai apa yang dapat dirinya lakukan (Bandura, 2010).

Pada proses afeksi, efikasi diri yang dimiliki individu akan mempunyai kemampuan coping dalam mengatasi besarnya stres yang di alami oleh individu pada saat situasi sulit. Coping ini membantu individu dalam mempengaruhi tingkat motivasinya. Pada proses selektif, individu akan menghindari aktivitas dan situasi yang individu percayai telah melampaui batas kemampuan coping dalam dirinya. Namun individu merasa telah siap melakukan aktivitas-aktivitas yang menantang dan memilih situasi yang dinilai mampu untuk diatasi (Bandura, 2010).

Berdasarkan penjelasan yang dikemukakan oleh ahli di atas, maka dapat dijelaskan bahwa secara dinamika psikologis efikasi diri mampu menjelaskan intensi perilaku seks pranikah pada remaja. Penelitian yang dilakukan Reuben, Obayemi, dan Oluwatosin (2016) membuktikan bahwa efikasi diri merupakan faktor psikologis yang sangat berpengaruh terhadap munculnya perilaku seks pranikah. Dalam hal ini keyakinan diri tersebut adalah seberapa percaya diri seseorang tentang menangani tugas, tantangan, dan konteks tertentu. Individu yang memiliki efikasi diri yang tiggi akan bertahan menghadapi rintangan dan tidak mudah terpengaruh untuk melakukan perilaku berisiko dalam hal ini perilaku seks pranikah.

Efikasi diri yang tinggi akan membuat individu teguh dan tidak mudah putus asa dalam mempertahankan perilaku. Berkaitan dengan intensi perilaku seks pranikah, individu yang memiliki efikasi diri tinggi cenderung mempunyai inisiatif untuk menunjukkan usaha yang lebih besar untuk memunculkan perilaku agar berdampak positif terhadap diri individu tersebut. Hal ini diperkuat juga oleh

Birrulwalidaini, email: asadlurrib@gmail.com 
Jurnal Psikologi Terapan dan Pendidikan

ISSN: 2715-2456

Vol. 1, No. 1, Mei 2019, pp. 45-53

hasil penelitian Boafo, Dagbanu, dan Asant (2014) membuktikan ada hubungan yang signifikan antara efikasi diri dengan penundaan melakukan seks pranikah pada remaja.

Hasil penelitian yang dilakukan oleh Winarni, Astirin, dan Dharmawan (2016) juga membuktikan bahwa terdapat hubungan efikasi diri dengan perilaku seks pranikah pada remaja. Remaja yang memiliki efikasi diri yang tinggi memiliki kemampuan untuk mengurangi perilaku seks pranikah. Hal ini menunjukkan bahwa individu yang memiliki efikasi diri tinggi akan berinisiatif untuk memunculkan suatu perilaku yang positif. Begitupun usaha yang dikerahkan dalam melakukannya juga akan lebih besar jika dibandingkan dengan individu yang memiliki efikasi diri rendah. Berdasarkan hasil analisis deskriptif di atas, dapat dijelaskan bahwa efikasi diri memiliki kontribusi terhadap intensi perilaku seks pranikah pada remaja.

\section{KESIMPULAN}

Efikasi diri merupakan salah satu aspek afektif tentang invididu itu sendiri yang paling berpengaruh dalam kehidupan sehari-hari. Remaja yang memiliki efikasi diri akan mampu menghadapi hambatan atau tantangan dalam hal mengatasi perilaku yang berisiko termasuk perilaku seks pranikah. Oleh karena itu setiap remaja dituntut memiliki efikasi diri yang tinggi sebagai salah satu upaya dalam mewujudkan perilaku sehat dan terhindar dari perilaku seks pranikah.

\section{DAFTAR PUSTAKA}

Abousselam, N.M. (2005). The moderator effect of future time perspective in the relationship between self-efficacy and risky sexual behavior. Thesis. Bloemfontein: University of the Free State. http://hdl.handle.net/11660/636.

Ajzen, I. (2005). Attitudes, personality and behavior (second edition). New York : Open university press mcgraw-hill education.

Alwisol. (2010). Psikologi kepribadian. UMM Press: Malang.

Bandura, A. (2002). Social cognitive theory of mass communication. Media psychology, 3, 265-299. Lawrence Erlbaum Associates, Inc.

Bandura, A. (2010). Self-efficacy. the corsini encyclopedia of psychology. doi:10.1002/9780470479216.corpsy083.

Baron, R.A., \& Byrne, D. (2005). Psikologi sosial. Jakarta: Erlangga.

Boeree, C.G. (2017). General psychology: Psikologi kepribadian, persepsi, kognisi, emosi \& perilaku. Penerjemah : Helmi J. Fauzi. Yogyakarta: Prismasophie.

Bogale, A., \& Seme, A. (2014). Premarital sexual practices and its predictors among in-school youths of shendi town, west Gojjam zone, North Western Ethiopia. Reproductive Health, 11(1). https://doi.org/10.1186/1742-4755-11-49.

Buhi, E.R. and Goodson, P. (2007). Predictors of Adolescent Sexual Behavior and Intention: A Theory- 
Jurnal Psikologi Terapan dan Pendidikan

ISSN: $2715-2456$

Vol. 1, No. 1, Mei 2019, pp. 45-53

Guided Systematic Review. Journal of Adolescent Health, 40, 4-21.
https://doi.org/10.1016/j.jadohealth.2006.09.027.

BKKBN. (2016). Survei demografi dan kesehatan Indonesia 2016: Kesehatan reproduksi remaja. Jakarta

Cavendish, M. (2010). Sex and society. London: Marshall Cavendish Corporation.

Cha, E. S., Doswell, W. M., Kim, K. H., Prochownik, D. C., \& Patrick T. E. (2007). Evaluating the theory of planned behavior to explain intention to engage in premarital sex amongst korean college students: A questionnaire survey. International Journal of Nursing Studie. 44(7), 1147-1157. http://10.1016/j.ijnurstu.2006.04.015

Chilisa, R., Tihabano, K., Vista, C., Pheko, M., Losike, N., Mosime, S., Mpeta, K., \& Balogun, S.K. (2013). Self-efficacy, self-esteem and the intention to practice safe sex among botswana adolescents. IOSR Journal of Humanities and Social Science. 9(2), 87-95. http://iosjournals.org/iosr-jhss/papers/vol9-issue2/L0928795.pdf.

Creswell, J.W. (2015). Penelitian kualitatif dan desain riset: memilih diantara lima pendekatan. Penerjemah: Ahmad Lintang Lazuardi. Yogyakarta: Pustaka Pelajar.

Crooks, R., \& Baur, K. (2013). Our sexuality. Belmont, CA: Wadsworth/Cengage Learning.

Dimotakis, N., Mitchell, D., \& Maurer, T. (2017). Positive and negative assessment center feedback in relation to development self efficacy, feedback seeking, and promotion. Journal of Applied Psychology, 102(11), 1514-1527. http://dx.doi.org/10.1037/ap10000228.

Djamba, Y.K., \& Kimuna, S.R. (2014). Are americans really in favor of interracial marriage? a closer look at when they are asked about black-white marriage for their relatives. Journal of Black Studies. 45(6), 528 -544. DOI: 10.1177/0021934714541840.

Huang, D. Y. C., Murphy, D. A., \& Hser, Y. I. (2011). Parental monitoring during early adolescence deters adolescent sexual initiation: discrete-time survival mixture analysis. Journal of Child and Family Studies, 20(4), 511-520. https://doi.org/10.1007/s10826-010-9418-z.

Irianto, K. (2015). Kesehatan reproduksi. Bandung : Alfabeta

Fishbein, M. \& Ajzen, I. (1975). Belief, attitude, intention, and behavior: An introduction to theory and research. Reading, MA: Addison-Wesley.

Lange, V., Kruglanski, A.W., \& Higgins E.T. (2012.). Handbook of theories of social psychology: Volume two. London: Sage Publications.

MacNeil S., \& Byers, E.S. (2009). Role of sexual self-disclosure in the sexual satisfaction of long-term heterosexual couples. Journal Sex Res. 46(1), 3-14. doi: 10.1080/00224490802398399 .

Reuben, O. S., Obayemi, O., \& Oluwatosin, D. (2016). Psychological predictors of premarital sexual relationship among in-school adolescents in a Western Nigerian city. Universal Journal of Public Health. 4(4), 196-202. doi:10.13189/ujph.2016.040405.

Rosdarni, Dasuki, D., \& Waluyo, S. D. (2015). Pengaruh faktor personal terhadap perilaku seksual pranikah pada remaja. Jurnal Kesehatan Masyarakat Nasional, 9(3), 214221. http://dx.doi.org/10.21109/kesmas.v9i3.567.g450.

Santrock, J. W. (2012). Perkembangan Anak (S. Gendis, ed.). Jakarta: Erlangga.

Sarwono, S.W. (2016). Psikologi remaja. Jakarta: PT. Raja Grafindo.

Birrulwalidaini, email: asadlurrib@gmail.com 
Jurnal Psikologi Terapan dan Pendidikan

ISSN: 2715-2456

Vol. 1, No. 1, Mei 2019, pp. 45-53

Sherf, E. N., \& Morrison, E. W. (2019). I do not need feedback! Or do i? Self efficacy, perspective taking, and feedback seeking. Journal of Applied Psychology. Advance online publication. http://dx.doi.org/10.1037/apl0000432.

Sugiyono. (2015). Metode penelitian pendidikan pendekatan kualitatif, kuantitatif, dan R\&D. Bandung: Alfabeta.

Suyono, H. (2011). Studi deskriptif konflik pemilukada: Analisis psikologi. Program Studi Psikologi Fakultas Psikologi Universitas Ahmad Dahlan.

Tsai, C.C., Chuang, S.C., Liang, J.C. \& Tsai, M.J. (2011). Self-efficacy in internet-based learning environments: A literature review. Journal of Educational Technology \& Society, 14(4), 222-240. https://www.learntechlib.org/p/75490/.

Watofa, Y.M., Suryanto \& Basuki, H. (2019). Premarital Sexual behavior among Papua women: a qualitative research. Journal of Educational, Health, Community Psychology. 8(2), http://dx.doi.org/10.12928/jehcp.v8i2.13049.

Winarni, Astirin, O.P., \& Dharmawan, R. (2016) Association between self-esteem, self-efficacy, peers, parental controls and sexual behavior in adolescents at high school, Surakarta. Journal of Health Promotion and Behavior, 1(1), 46-53. https://doi.org/10.26911/thejhpb.2016.01.01.07.

Winarni, W. (2017). Efikasi diri dan perilaku seksual pranikah remaja SMA. Gaster: Jurnal Kesehatan, 15(2), 232-240. 